\title{
GUERRILHA MAMALUCA: UM ESTUDO DA POESIA DE SEBASTIÃO NUNES A PARTIR DA ARTICULAÇÃO ENTRE POESIA E TÉCNICA
}

Fabrício Marques de 01 iveira*

RESUMO:

\begin{abstract}
Nos poemas de Sebastião Nunes reunidos nas Antologias Mamalucas, o autor apropria-se parodisticamente de técnicas publicitấrias e jornalísticas, do design gráfico e da citação para criticar a sociedade de consumo, a classe média e as estruturas de poder. 0 poeta promove, assim, uma estética da pilhagem, por meio de colagens e interferências das mais diversas naturezas.
\end{abstract}

PALAVRAS-CHAVE: Sebastião Nunes, poesia brasileira contemporânea.

Sátiro multimídia, bruxo de Sabará, Sebastião Nunes (1938) é na verdade um grande humanista: nada do que é humano the é estranho. Sua obra aponta menos para uma profunda descrença no ser humano e mais para a redenção que eventualmente possa vir (também para o autor, que não se exclui do processo) sob a forma do humor e do escárnio. Sua tarefa, hercúlea e quixotesca, é a de mostrar que o cinismo, a hipocrisia, a mesquinharia e a corrupção são intrínsecas à condição humana, e ele não nos deixa esquecer.

Ninguém nasce Sebastião Nunes impunemente. Dono de uma produção literária e poética vestida com a indumentária da - notável - originalidade, o artista gráfico e poeta permaneceu ignorado pelas editoras e pela mídia por muitos anos, considerandose o período em que lançou o primeiro livro, de poesia, em 1968. Mesmo tornando-se a mais notória unanimidade entre escritores, depois de ter publicado 21 livros (dez

* Doutor em Letras: Poéticas da Modernidade (Área de concentração: Literatura Comparada), 2004. 


\section{EMTESE}

Belo Horizonte, v. 9, p. I-28I, dez. 2005

de poesia, três de ficção, um ensaio e sete infanto-juvenis), ainda permanece desconhecido do grande público.

Sebastião Nunes é caso especial da poesia brasileira. Especial porque não é só poeta, mas poeta $e$ artista gráfico $e$ editor de seus próprios livros. Sua condição de poeta é indissociável das outras qualificações. Como artista gráfico, criou a programação visual e foi o responsável pelas fotos, ilustrações, produção gráfica, arte-final e apropriações indébitas de seus livros. Sua produção poética foi reunida nas Antologias Mamalucas 1 e 2, duas antologias que trazem colagens e interferências do próprio autor, sobre reproduções fotográficas de material anônimo e disperso em revistas, jornais e publicações publicitárias, catálogos de laboratório e lojas de departamentos, entre outras fontes. Em raríssimos casos, o material trazia autoria, mas essa se perdeu com o tempo. Porque como quase todo fora retirado de publicações publicitárias americanas-do-norte, "uma atividade perniciosa num país indesejável", o autor considera tal apropriação "uma pequena revanche contra as apropriações do que vimos sendo vítimas há séculos".

As Antologias Mamalucas 1 e 2 são o conjunto (e não apenas o resumo) de 20 anos de poesia, aliás toda a poesia que publicou. Pouquíssima coisa foi excluída. Sebastião Nunes apreciou muito fazer esses dois livros, pois sua poesia estava muito dispersa, difícil de agrupar, pelos vários formatos em que foram editadas. Finis Operis, por exemplo, era um envelope, com papéis de tamanhos e tipos diferentes. 0 Suicídio do Ator era um cartaz com frente e verso. Foi uma espécie de ordem no caos, principalmente porque sabia que não voltaria a fazer poesia. E sabia porque tinha feito uma circunavegação na própria linguagem. "E, como o uróboro (ou uróvoro) dos alquimistas medievais, mordi a ponta do meu rabo estético. Digamos, finalmente, que foi a satisfação do dever cumprido. 0 lento, suado e progressivo dever do poeta, descobrindo e explorando sua mina de palavras e de imagens".

Uma forma de se ler as Antologias Mamalucas é partir de uma articulação entre poesia e técnica. Sabemos que, para os poetas modernos, mais precisamente escritores-críticos modernos como Octavio Paz, Michel Butor, Haroldo de Campos, T. S. Eliot, Jorge Luis Borges, Ítalo Calvino e Phillipe Sollers, a linguagem literária readquire seu sentido original de poiesis, arte da linguagem que exige uma technè; essa technè ganha, na modernidade, uma homologia (não uma identidade) com as formas 
tecnológicas de produção material na sociedade moderna, tal como observou Perrone Moisés (1998: 154).

Técnica é uma palavra que esses escritores usam sem o receio romântico de que esta contrarie o "mistério" da inspiração. Para eles, na poesia como na prosa, o resultado não depende apenas da inspiração, mas de uma técnica que precisa ser aprendida e desenvolvida, e a partir daí, reinventada e nova. De qualquer forma, escrever é um ofício. "Os maiores elogios dos escritores-críticos modernos (Paz, Butor, Campos, Eliot, Borges, Calvino, Sollers) vão para aqueles que foram ou são mestres, não apenas por terem sido reverenciados pela tradição, mas por terem sido exímios em sua arte, e por suas lições permitirem aplicações e desenvolvimentos atuais" (Perrone-Moisés, 1998: 155).

Barthes observou que o escritor, desde que sua condição deixou de ser considerada uma vocação ou uma missão recebida do Além, sentiu a necessidade de se afirmar como um profissional. A técnica e o ofício tornaram-se, para ele, imperativos éticos.

A relação entre poesia e técnica permite constatar, também, que tem sido desconsiderada, ou mesmo neglicenciada, em grande parte dos estudos que pretendem analisar textos poéticos, a dimensão extra-verbal. Por esse motivo, as referências ou citações relacionadas a um objeto de estudo específico tornam-se perigosas, em certa medida, porque retiradas de um palco em que a tipografia e as ilustrações são cenário e figurino, e até personagem. É o caso da poesia de Sebastião Nunes, que se articula na idéia de mistura, de integração num único elemento poético de códigos verbais e visuais; mas sobretudo nas tensões entre texto verbal e imagem.

Vistas em conjunto, as técnicas com as quais Sebastião Nunes manteve contato durante a produção dos poemas das Antologias Mamalucas, mesclando verbal e não-verbal, compuseram o mosaico formador de uma visualidade diagramática. Essa visualidade ficou evidenciada por seu caráter híbrido, mantido em todas as modalidades desenvolvidas pelo poeta.

Para proceder sua guerrilha particular, Sebastião Nunes privilegia os efeitos parodísticos e a sátira menipéia, essa última um gênero do campo cômicosério caracterizada pela recorrência, nos poemas, de alguns procedimentos: opção 


\section{EMTESE}

Belo Horizonte, v. 9, p. I-28I, dez. 2005

pelos problemas sociopolíticos contemporâneos, gosto pelas cenas de escândalo, pelas condutas excêntricas, pelos discursos e declarações inoportunas, amplo emprego dos gêneros intercalados e a fusão dos discursos, assim como de contrastes agudos e jogos de oxímoros. Essas observações valem não só para a produção poética do autor, mas também para a criação em prosa, como História do Brasil e Sacanagem Pura, por exemplo.

A conexão com a sátira menipéia é também apreendida pela percepção de um segundo mundo erguido ao lado do mundo oficial e oficialesco: nesse mundo ao inverso, uma vida ao contrário se oferece ao leitor, com jogos de mésalliances (aproximação dos contrários) e profanação: o autor nega tudo quanto for institucionalizado, estabelece um embate contra o poder e suas engrenagens, abarcando as esferas política e literária, colocando à prova todo um sistema de valores e regras.

A crítica principal do autor é dirigida aos jogos de poder, à idiotização da classe média condenada à ilusão do consumismo. Para efetivar essa crítica e causar certo estranhamento ao leitor, o autor utiliza-se de apropriações parodísticas dos discursos publicitário, jornalístico e fotográfico, apropriações metalingüísticas, colocando sob suspeita o próprio fazer poético e a poesia de um modo geral, além de praticar intervenções no design gráfico e no campo da perigrafia do texto.

Gostaria de anotar quatro observações que surgem quando se lê os poemas de Sebastião Nunes sob o ponto de vista da apropriação e da técnica:

1) A apropriação das técnicas publicitârias fornece a SN os próprios meios de disparar contra a poesia e a própria publicidade. Esta última não está mais apenas nos anúncios, mas nos próprios veículos de comunicação. Na visão crítica de SN, o consumo se revela um campo político e poderoso elemento de dominação social, na medida que expõe uma sociedade produtora de privilégios, e, intrínseca a essa sociedade, a publicidade, que ao mesmo tempo satisfaz e fomenta os desejos dos consumidores. Nesse mundo em que a publicidade pode ser lida como um ritual, consumir é participar de um cenário de disputas por aquilo que a sociedade produz e pelos modos de usá-10.

Nesse ponto, anota-se uma primeira contradição, entre ordem e desordem, sujeira e purificação. Do seguinte modo: na reprodução serial de uma mesma imagem 
ou texto verbal - em poemas como Habeas corpus, Zovos e A Cidade de Deus -, é sublinhado o caráter de padronização [identificada com a ordem, com coisas ordenadas] da publicidade e da sociedade de consumo. Para combater tal caráter, SN adotou um "comportamento-poluição": adota uma prática de mistura, de celebração da mestiçagem entre o verbal e o não-verbal, de festejar mesmo a sujeira, a impureza, mas, ressalte-se, tudo envolto em poemas milimetricamente construídos.

Em séries à maneira de 0 poeta como, o autor aponta para a reconquista criativa de espaços públicos, vinculando de certa maneira consumo e cidadania. Por um certo ângulo, opor-se ao mundo dos bens de consumo pode levar a perder as chances de uma ação política, e reivindicar o direito até mesmo ao supérfluo. Desse modo, a crítica deveria recair não ao consumo propriamente dito, mas ao consumismo.

2) A apropriação das técnicas de design gráfico permite aumentar a eficácia da estética de provocaçam de SN, seja na colagem de paródias, montagem ou fotomontagem. No processo de composição dos poemas, o poeta buscou o equilíbrio dos elementos na página, tanto ao fazer uso do ideal clássico da simetria quanto da assimetria - o que confere uma significativa unidade a sua obra. Apesar de praticar uma pluralidade de formas, em alguns poemas a página em que repousam é baseada num eixo central. Por outro lado, a assimetria foi o princípio motor de poemas como Serenata brasiliense e Serenata número dois. - múltiplas opções e tensões provocadas pela inexistência de um centro definido. Outra solução encontrada pelo poeta foi o arranjo dos elementos na página sobre um eixo descentralizado, daí resultando tensões entre a área do grafismo e do contra-grafismo (espaços em branco, por exemplo). Nessas incursões, SN privilegiou sobretudo o contraste de tamanho ou de escalas, como ocorre por exemplo em Procissão da chuva e Suma escatológica.

3) A apropriação das técnicas jornalísticas funciona como motor contraditório das narrativas a que se referiam, na medida que desautorizam o que pretendem apresentar, em tom de documento reatualizado como farsa. Um primeiro aspecto reside no que se pode chamar de estratégia do despiste a referência textual desabona a imagem aludida, e vice-versa. 0 autor embaralha as fontes com as falas que supostamente proferiram. Assim, por essa ligação espúria entre citação e fonte, ao invés de ser legitimada, a própria narrativa é colocada sob suspeita. É o que se dá em textos como Blablablá ecumênico e Auto da Virgem Ensimesmada. 


\section{EMTESE}

Belo Horizonte, v. 9, p. I-28I, dez. 2005

Outro aspecto se concentra nas recriações de reportagem que se dão a ver principalmente nas pequenas histórias de Papéis higiênicos, registros de mortes que lembram os obituários dos jornais impressos. Nesses poemas, muitas das noções [como o acontecimento] e técnicas do jornalismo - títulos, chamadas, fotojornalismo estão a serviço da desarticulação do texto - como referência, basta lembrar da mescla de hai-kai e notícia policial Serenata em B Menor, ou da dicção e da ilustração documentais desmentidas a todo instante em Procissão da Chuva. 0 poeta, mais do que aquele que produz informações, é aquele que intervém nas informações.

4) A apropriação dos elementos da perigrafia textual intensifica o caráter dessacralizador do poema que se nega enquanto poema, ao mesmo tempo que busca legitimação na rede de citações que perpassam o texto. Trata-se de uma rede dinâmica e viva, que atua a plenos pulmões sobre e com textos e imagens. São citações tanto em nível verbal quanto não-verbal, palavras que contaminam imagens, imagens que contaminam palavras, reforçando o estranhamento: a própria citação é um corpo estranho no texto. 0 objetivo do poeta de abastecer seus textos de notas de rodapé e de epígrafes é, paradoxalmente, esvaziá-10 de erudição, "sujá-10" por todos os lados. Bricoleur, o autor tenta reconstruir, em meio a despojos e dejetos, algo que se perdeu, está se perdendo.

Essas apropriações ocorrem num palco em que não há uma hierarquização entre palavra e imagem. 0 que está em jogo na estética desenvolvida por SN é um gênero híbrido, mestiço, mameluco, em que imagem e texto verbal têm a mesma importância, integrados um ao outro. A equivalência entre ambos apresenta uma relação de complementaridade, ou de determinação recíproca. Nessa visualidade - que se define pela soma de todos os elementos do poema - observa-se a superposição de diagramações, em que são estabelecidos níveis de contradição e até mesmo de discrepância entre as duas formas, ainda que a integração entre as duas formas não se dissolva.

Nessa encruzilhada sígnica, palavra e não-verbal se chocam, se contaminam, em igualdade de forças. Quanto às imagens, sofrem interferências de toda ordem. Quanto ao texto verbal, é constituído muitas vezes de elementos como a escatologia, o palavrão, a ausência de determinadas letras em algumas palavras, "erros" de português: sujar as palavras e as imagens é um modo de provocar, incitar, violentar o leitor. 
Um esforço de contextualização é necessário para identificar uma tradição de vanguarda à qual se ligaria SN. 0 nome mais evidente, marco das realizações em torno da ampliação do conceito de poesia além do especificamente verbal, é Mallarmé, que inaugurou uma nova etapa na história da poesia ocidental. Dentre aqueles que estabeleceram soluções inventivas para des-arranjar o poema na folha de papel, o poeta francês ocupa um lugar de destaque, mas ficou restrito à chamada poesia espacializada, voltada para a disposição tipográfica das palavras em oposição ao branco da página. Em outros registros, mas seguindo as diretrizes de espacialização do poema, a possibilidade fisiognômica de Apollinaire e a tortografia de e. e. cummings apresentam aproximações com a estética de SN. Já o poeta português Alberto Pimenta aproxima-se de Nunes por outras vias. Ambos são antilíricos que procuram dessacralizar o poético, e, ainda, demonstram uma maior abertura em relação às dimensões gráficas e de recursos como a colagem e a mistura de linguagens.

Os manuais de guerrilha ensinam que a mobilidade tática, o conhecimento superior do terreno e o adequado poder de ataque são os pontos essenciais de qualquer insurreição bem sucedida. Os guerrilheiros precisam desenvolver e explorar essas três vantagens em potencial. A primeira é uma mobilidade maior do que aquela que as forças militares convencionais, que se the opõem, possuem. A segunda é um conhecimento detalhado e profundo das zonas onde ocorrem as lutas. Sendo naturais do campo de batalha, os guerrilheiros tendem a conhecer melhor do que os soldados que penetram na região para restaurar a ordem. A lógica desses procedimentos também vale para a tática guerrilheira de Sebastião Nunes, pois aqui ainda está-se falando de procedimentos técnicos.

Uma das táticas mais usadas na guerra irregular e não-convencional era a sabotagem, ou a destruição clandestina de propriedade. Os camponeses franceses e os primeiros operários industriais descobriram o valor do sabot, ou sapatos de madeira, como armas destrutivas. Durante as greves ou recessos um sabot atirado dentro da maquinaria ou simplesmente sapateado sobre qualquer objeto que fosse quebrável produzia uma quantidade considerável de danos.

Resultado do desenvolvimento tecnológico pós-Revolução Industrial, a poesia de SN, em relação à própria literatura brasileira, pode ser vista como uma anomalia, um elemento que não se ajusta a um dado conjunto ou série, empenhado que o poeta está em sabotar todo um sistema de valores. 


\section{EMTESE}

Belo Horizonte, v. 9, p. I-28I, dez. 2005

Fischer (2003) dedica o último capítulo de seu recente inventário sobre a literatura brasileira aos "malucos, irônicos, humoristas", os "singulares", aqueles autores - das mais diversas faturas - "condenados a incomodar o leitor": Gregório de Matos, Luîs Gama, Qorpo Santo, Bernardo Guimarães, Sousândrade, Machado de Assis, Campos de Carvalho, Ivan Lessa, Millôr Fernandes, José Agripino de Paula e Carlos Sussekind. Poderíamos acrescentar aí - entre os que afinam o coro dos descontentes - o nome de Sebastião Nunes.

NOTAS:

1. Citações extraídas da apresentação do autor às antologias citadas.

2. Depoimento inédito ao autor desta tese. Todas as citações desta parte do trabalho constam do mesmo depoimento, realizado em junho de 2000 .

ABSTRACT :

In the Sebastião Nunes's poems, gathered in Antologias Mamalucas, the author parodies techniques used in advertising, journalism and graphic design as well as citations, in order to critize consumerism, the middle classes and the power structures. In this fashion, the poet endorses the aesthetics of pillage using collage and interference.

KEY WORDS: Sebastião Nunes, brasilian poetry.

REFERÊNCIAS BIBLIOGRÁFICAS

FISCHER, Luís Augusto. Literatura Brasileira. São Paulo: Abri 1, 2003.

PERRONE-MOISÉS, Leyla. Altas Literaturas. São Paulo: Companhia das Letras, 1998. 